\section{Nerve Morbidity after Mandibular Third Molar Surgery: A Prospective Study of Two Cohorts of Patients}

\section{Abstract}

Background: The surgical extractions of impacted mandibular third molars are sometimes associated with nerve morbidity.

Objective: To determine the incidence of nerve morbidity after mandibular third molar surgery and compare the complications from the inferior alveolar and lingual nerves in two cohorts of patients.

Patients and methods: This prospective study was an investigation of two cohorts of patients within duration of four years. The sample size was composed of 212 subjects, made up of 28 patients who had their impacted third molars in close contact with the inferior alveolar canal and 184 patients that did not have their molars in contact. The predictor variables were age, gender, type of impaction, indications for extraction, difficulty index and duration of surgery. The outcome variable was the development of neuro-sensory complication(s) after treatment. Descriptive and bivariate statistics were computed and the $P$ value was set at 0.05 .

Results: There was no significant relationship between the predictor variables in the two groups. The result showed that $6 / 212(2.8 \%)$ patients complained of numbness of the ipsilateral lower lip and part of the cheek. Out of this $4 / 28(14.3 \%)$ were in those that had their molars in close contact with inferior alveolar canal while 2/184 (1.1\%) were cases that didn't make contact. No complication occurred that was related to the lingual nerve. Conclusion: Nerve morbidity occurred after third molar surgery and the incidence is commoner in cases where the third molar made contact with inferior alveolar canal.

Keywords: Mandible; Impacted third molar; Nerve morbidity; Complications

\section{Charles E Anyanechi ${ }^{1}$ and Birch D Saheeb²}

1 Oral and Maxillofacial Unit, Department of Dental Surgery, University of Calabar/ University of Calabar Teaching Hospital, Calabar, Nigeria

2 Department of Oral and Maxillofacial Surgery, University of Benin/University of Benin Teaching Hospital, Benin City, Nigeria

\section{Corresponding author:}

Dr. Charles E Anyanechi

” ceanyanechi@gmail.com

Department of Dental Surgery, University of Calabar/University of Calabar Teaching Hospital, Calabar, Nigeria.

Tel: +2348059383922

Citation: Anyanechi CE, Saheeb BD. Nerve Morbidity after Mandibular Third Molar Surgery: A Prospective Study of Two Cohorts of Patients. J Neurol Neurosci. 2016, 6:4.

Received: October 15, 2015; Accepted: December 02; 2015; Published: December 07,2015

\section{Introduction}

The surgical extraction of impacted mandibular third molars is a common procedure carried out in the dental surgery, and oral and maxillofacial surgery setting [1,2]. Some impacted mandibular third molar teeth are in close proximity to the lingual, inferior alveolar, mylohyoid and buccal nerves. The nature of the impactions and the complexity of the surgical procedures endanger particularly both the lingual and inferior alveolar nerves $[3,4]$. The risk factors of these nerve injuries according to earlier researchers include the depth of impaction, roots proximity to the inferior alveolar canal, accessing the impacted tooth from the lingual side rather than the buccal side during extraction, rough manipulation and/or detachment of the raised lingual flap $[5,6]$. The incidence of inferior alveolar nerve and lingual nerve injuries reported earlier ranges from $0-22.0 \%$ and fortunately, most of these injuries undergo spontaneous remission during the postoperative recovery period [4-7].

As the majority of these nerve injuries result in transient sensory disturbance, however in some cases, permanent paraesthesia, hypoaesthesia or dysaesthesia can occur requiring appropriate treatment $[8,9]$. These sensory disturbances can be devastating to the patients because of its effect on speech, swallowing, mastication and social interaction, which may invariably adversely affect the patients' quality of life $[6,7,10]$. Consequently, 
nerve morbidity following the surgical extraction of impacted mandibular third molar constitute one of the most frequent causes of complaints by patients and sometimes litigation in dental practice [7]. Unlike in most other centres across the globe, our experience have shown that in the study environment, some dental surgeons in the bid to quickly satisfy their patients' desire embark in the surgical extraction of impacted mandibular third molar without proper clinical assessment, endangering these nerves in the process which sometimes lead to temporary or permanent nerve damage.

This prospective study determined the incidence of nerve morbidity after mandibular third molar surgery and compared the complications arising from morbidities of the inferior alveolar and lingual nerves in two cohorts of patients who had surgery of impacted mandibular third molars at our centre over a period of four years.

\section{Patients and Methods}

This prospective, single-blinded clinical study was undertaken to determine the incidence of nerve morbidity after mandibular third molar surgery and compared the complications arising from the inferior alveolar and lingual nerves in two cohorts of patients. Two hundred and twelve-male and female patients between the ages of 17 and 44 years who were indicated for extraction of impacted mandibular third molars under local anaesthesia were studied. The Research and Ethics Committee of our institution approved the study which was carried out in accordance with the Helsinki Declaration of 1975, as revised in 2000. Informed consent was also obtained from each subject. The study duration was four years, from May 2009 to April 2013.

The 212 subjects studied were in two groups. In group A patients, the impacted mandibular third molars were in close contact with inferior alveolar canal ( $n=28$, Figure 1 ). In group B, the patients' impacted mandibular third molars were not in close contact with the inferior alveolar canal $(n=184$, Figure 2).The anatomical relationship between the inferior alveolar nerve and the impacted third molars were judged with oblique lateral radiograph of the affected side as recommended by Rood and Shehab [11] in an attempt to predict the likelihood of nerve damage during surgery.

The inclusion criteria were subjects with mesioangular, distoangular, vertical and horizontal impactions with a difficulty index of 3-8 as specified in the Pederson's criteria [12]. Also included were non-smokers, subjects not on steroid therapy or having any other systemic condition that may interfere with healing of surgical wound. The surgery of each impacted tooth lasted for 30 minutes. Impacted mandibular third molar teeth associated with lesions, patients that require more than one extraction, pregnant and lactating mothers and surgical procedures that lasted more than $\mathbf{3 0}$ minutes, including subjects who did not meet the inclusion criteria were excluded from the study.

The surgical extraction was done by the same surgeon and assistant in the same dental surgery environment. Local anaesthesia was achieved using $2 \%$ lidocaine with 1: 80,000 adrenaline. A full-thickness incision was made down to the bone to prepare a 3-sided mucoperiosteal flap with the relieving incision as far forward as the distal one-third of the buccal surface of the second molar. Incision was not made on the lingual side and therefore the lingual mucoperiosteal flap was not raised and reflected. The buccal flap was reflected using Howarth's periosteal elevator and osteotomy was done using the buccal guttering technique. Using a round bur mounted on a straight hand piece, bone was removed under constant irrigation with $0.9 \%$ normal saline solution. The tooth was delivered with a coupland elevator and toileting of the sockets was done, haemostasis was achieved and the flaps were replaced by suturing with $3 / 0$ vicryl sutures. The sutures were placed at the distal and mesial relieving incisions and the interdental papilla immediately distal to the adjacent second molar tooth. The duration of surgery starting from the time of the first incision to the placement of the last suture

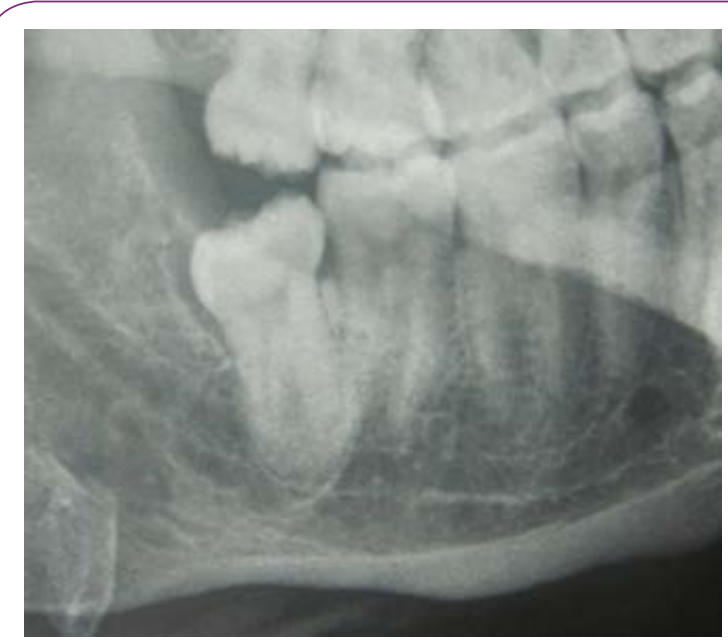

Figure 1 Radiograph showing roots of disto-angularly impacted mandibular third molar in close proximity to the inferior alveolar canal.

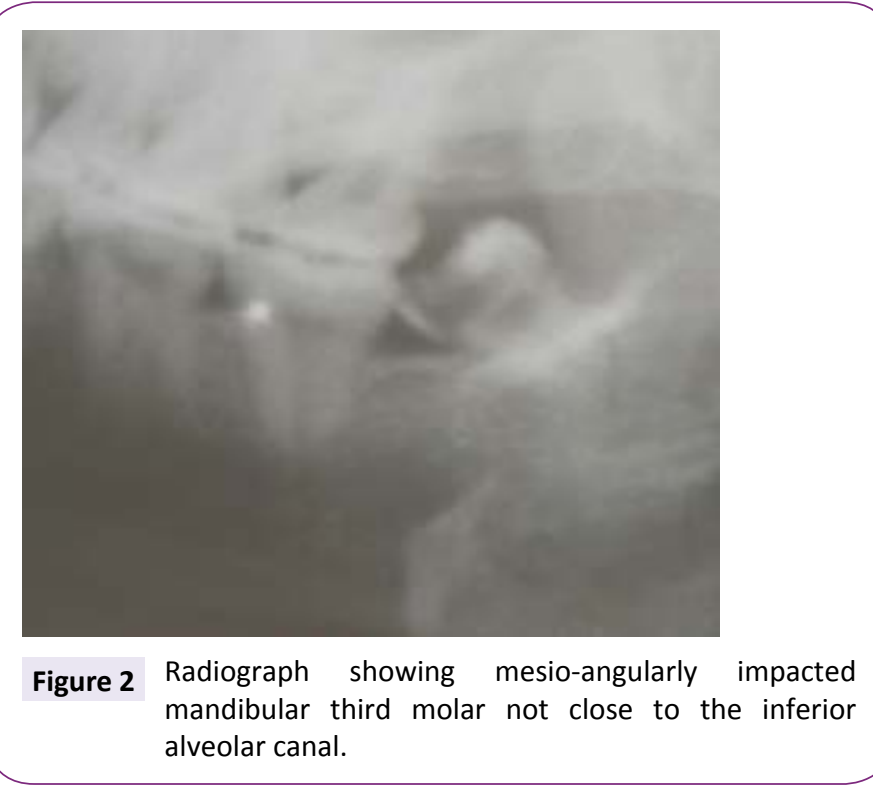


material was recorded in minutes. The patients were given the same oral analgesics and antibiotics (naproxen sodium 550mg 12 hourly for 5 days; clindamycin 150mg 12 hourly for 5 days), and postoperative instructions.

The subjects were reviewed postoperatively in a blinded manner by the same surgeon on the third and seventh days and in the subsequent two weeks. Those who had sensory disturbances were further reviewed at one month, three months, six months and yearly for up to two years. Using the patients' own subjective report, sensory abnormality of the lower lip/cheek and tongue was assessed during the follow-up period. The progress of recovery of the sensory disturbances was monitored by responses to pin prick of the lower lip/cheek, [3] and no sensory disturbance of the tongue was recorded.

The data obtained were analyzed using EPI INFO 7, 0.2.0, 2012 version software (CDC, Atlanta, GA, USA). For analysis, descriptive statistics, and test of significance were used. The $\chi^{2}$ test was utilized to compare the proportion of the descriptive variables between both groups, whereas the Student's t- test was used to compare the means of continuous variables between the two groups at a $95 \%$ confidence interval. $P$ value of $<0.05$ was considered significant.

\section{Results}

There was no significant association between the demographic and operative characteristics of the patients in the two groups studied as shown in Table 1. The operative time was found to be 0.5 minutes longer in those patients whose third molar teeth were in close contact with the inferior alveolar canal (Group A), but this was not significant ( $p=0.24$, Table 2 ).

Table 1 Demographic and operative features of patients. Figures are expressed as number (\%) unless otherwise specified.

\begin{tabular}{|c|c|c|c|c|}
\hline Description & Group A & $\begin{array}{l}\text { Group B } \\
\text { p-value }\end{array}$ & Test & $p$-value \\
\hline \multicolumn{5}{|l|}{ Gender } \\
\hline Male & $16(57.1)$ & $96(52.2)$ & $\chi^{2}=0.913$ & 0.62 \\
\hline Female & 12 (42.9) & $88(47.8)$ & & \\
\hline \multicolumn{5}{|l|}{ Age (years) } \\
\hline Mean (SD) & $26.7(6.1)$ & $25.9(5.74)$ & $t=1.687$ & 0.19 \\
\hline \multicolumn{5}{|l|}{ Impaction } \\
\hline Mesioangular & 12 (42.9) & $84(45.7)$ & $\chi^{2}=0.79$ & 0.93 \\
\hline Vertical & $9(32.1)$ & $56(30.4)$ & & \\
\hline Distoangular & $5(17.9)$ & $32(17.4)$ & & \\
\hline Horizontal & $2(7.1)$ & $12(6.5)$ & & \\
\hline \multicolumn{5}{|l|}{ Indications } \\
\hline Pericoronitis & 19 (67.8) & 114 (61.9) & $\chi^{2=} 5.343$ & 0.56 \\
\hline $\begin{array}{l}\text { Apical } \\
\text { periodontitis }\end{array}$ & $4(14.3)$ & 33 (17.9) & & \\
\hline Pulpitis & $3(10.7)$ & $29(15.8)$ & & \\
\hline Prosthodontics & $1(3.6)$ & $6(3.3)$ & & \\
\hline Orthodontics & $1(3.6)$ & $2(1.1)$ & & \\
\hline \multicolumn{5}{|l|}{ Difficulty index } \\
\hline Mean (SD) & $6.2(2.1)$ & $5.9(2.7)$ & $t=1.041$ & 0.38 \\
\hline
\end{tabular}

Table 2 Duration of operative procedure for the two groups of patients

\begin{tabular}{c|c|c|c|c|c|}
\hline & \multicolumn{5}{c}{ Duration (minutes) } \\
Group & Mean (SD) & df & t & p-value & Mean difference \\
\hline A & $27.8(3.5)$ & 4 & -1.45 & 0.24 & -0.5 \\
\hline B & $27.3(2.3)$ & & & & \\
\hline
\end{tabular}

The result showed that $6 / 212(2.8 \%)$ patients complained of numbness of the ipsilateral lower lip and part of the cheek following treatment. Out of this, $4 / 28$ (14.3\%) in mandibular third molars group A while 2/184 (1.1\%) were in group B. These complaints were made between three days and two weeks after treatment. However, these complaints resolved spontaneously between six weeks and four months after the onset. No recurrence of numbness of the ipsilateral lower lip/part of the cheek was recorded at two years postoperative review. No patient complained of neuro-sensory disturbance of the lingual nerve.

The six patients that had complications were 2 males and 4 females, and their ages ranged between 24 and 39 years with a mean age of 31 years. The four cases that complained of numbness in Group A had vertical impaction $(n=2)$, disto-angular $(n=1)$ and horizontal $(n=1)$ impactions, whereas in group $B$, one disto-angular and one vertical impaction were involved. There were no mesio-angular impactions in the two categories. None of the patients with postoperative complications was lost to followup.

\section{Discussion}

This study determined the incidence of nerve morbidity involving the inferior alveolar and lingual nerves after mandibular third molar surgery and the results were compared in two cohorts where the mandibular third molar teeth were in close contact with the inferior alveolar canal and in those cases where the third molars were not close to the canal. The overall incidence of nerve morbidity of $2.8 \%$ was recorded and these were temporary nerve paresis which affected the distribution of the inferior alveolar nerve. There was no neuro-sensory complication of the tongue. This observation falls within those of GargalloAlbiol et al. [13] where the incidence of temporary disturbances affecting the inferior alveolar nerve and the lingual nerve was found to be in the range of $0.28-13.0 \%$. On the contrary, it is lower than the $13.4 \%$ reported by Wasiu and Lagos [14] who also observed that a similar incidence of sensory deficit and morbidity was present in the patients who do not have clinically sound indications for surgery when compared to those with accepted symptoms. A further review of the literature showed that the true incidence cannot be established because in most studies, unlike the present one, surgery was performed by many different surgeons, surgical technique was not standardized, inclusion and exclusion criteria were not provided, and some appear to be based on surgeries performed under both local and general anaesthesia $[4,7,8]$. Furthermore, the incidence of nerve injury may depend upon whether the sensory deficit was established objectively by the clinician or was based on a subjective patient assessment [7]. However, the most sensitive indicator of a sensory abnormality is the patients' own subjective 
report, as minor sensory disturbances may not be detected by objective testing $[3,7]$. There was no lingual nerve involvement in the present study because the lingual mucoperiosteal flap was not raised. Similar study by Yeh et al did not find any single incidence of neuro-sensory abnormality affecting the tongue in their series although they used the lingual split bone technique to extract the impacted third molars [15]. Contrary to this, neurosensory deficits affecting the tongue have been reported in the literature [7]. Also, it has been documented that raising a lingual mucoperiosteal flap, clumsy instrumentation, and lingual plate fracture may result in lingual nerve paraesthesia and to avoid this, it is essential to protect the lingual nerve from direct trauma with instruments by positioning a periosteal elevator underneath the lingual periosteum [16]. Currently, as was done in this study, there is a trend of not raising a lingual mucoperiosteal flap, in an attempt to reduce the incidence of lingual nerve dysaethesia during third molar surgery [13].

However, injuries to both the lingual and inferior alveolar nerves vary and depend on the experience of the surgeon, increased age of the patient, depth of impaction, lingual angulation of the third molar, presence of overlying ramus, lingual flap elevation, perforation of the lingual plate during surgery, exposure of the nerve, increased operating time, surgical approach used, difficulty of the case, and it has been reported that the female gender are more predisposed $[7,16,17]$. On the contrary, Cheung et al. [18] stated that gender, age, raising of a lingual flap, protection of the lingual nerve with a retractor, removal of disto-lingual cortex, tooth sectioning and difficulty in tooth elevation were not found to be significantly related to inferior alveolar or lingual nerves injury. Paradoxically, as noted in this study, neuro-sensory disturbance may occur following removal of impacted third molar that show none of these features, and may not occur even when there appears to be a clear evidence of a close relationship between the canal and tooth roots [7].

Most of these factors may not have influenced the outcome of the present study as they were standardized, and were not significant when the study variables were compared in the two cohorts of patients.

Although complications may be attributed to many confounding variables including genetics, [5-7] this temporary inferior alveolar nerve paresis may be due to the postoperative oedema that developed after the surgical procedure coupled with the impaired drainage of the extraction sockets because of the sutures placed across the sockets. Also as documented in the literature, [7] the technique used for the surgery determines to some extent the probability of injury to inferior alveolar nerve or lingual nerve and consequently may have influenced the outcome of the present study.

The patients who had complications in the present study were all in their third and fourth decades of life. Age is considered a risk factor for inferior alveolar nerve injury following third molar surgery. Elena et al., [19] stated that older patients are at an increased risk and in some cases may lead to incomplete recovery from chin and lip numbness due to decreased nerve regeneration or neuronal plasticity. However, all our patients recovered completely from their neuro-sensory deficit.

In the present study, more females were affected than males. This is consistent with earlier reports $[7,16]$. The reason is poorly understood but some researchers attributed it to males being able to recover earlier from the effects of the surgical trauma than females $[16,18]$. However, the role of genetics to the predisposition of the female gender cannot be ruled out.

Vertical, disto-angular and horizontal impactions were the types of impaction that lead to inferior alveolar nerve neuro-sensory deficit in the two cohorts studied. This is consistent with the reports in the literature and affirmed the belief of earlier researchers that the more severe the impaction and subsequently the difficulty of the surgical procedure, the more likely the development of postoperative complications [7,16-18].

All the patients in the present series completely recovered spontaneously from their complications between six weeks and four months. The available literature shows that the greatest probability of recovery occurs in the first three months and the probability of recovery from inferior alveolar nerve injury is about $60 \%$ after three months, $55 \%$ in six months, $45 \%$ at nine months, and $17 \%$ even up to 15 months post-injury $[7,16]$. This study recorded $100 \%$ recovery after four months. Treatment is indicated when after three months there is still moderate or severe sensory impairment or there is neuropathic pain [16]. Fortunately in our series, no treatment were instituted after three months and the patients recovered from their nerve morbidity.

\section{Conclusion}

The surgical procedure to extract impacted mandibular third molars can be associated with the risk of nerve injuries, and adequate pre-operative assessment is required to identify such cases and inform the patient of its possibility. This study therefore have shown that inferior alveolar nerve disturbances can occur following third molar surgery and that the incidence is more in patients with factors that predispose to it. Lingual nerve disturbance was not recorded in the present study because of the surgical approach used to extract the third molars. Post-operative assessment should be made at timely intervals, to diagnose these neuro-sensory complications that most often arise at an early stage, so that appropriate treatment can be instituted early, when the complications fail to resolve spontaneously, in order to avoid unnecessary complaints by the patients and litigation that might follow.

\section{Conflict of Interest}

The authors declare no conflict of interest in the execution of this study. 


\section{References}

1 Contar CMM, Oliveira P, Kanegusuku K, Berticelli RS, Azevedo-Alanis LR, et al. (2010) Complications in third molar removal: A retrospective study of 588 patients. Med Oral Patol Oral Cir Bucal 15: e74-78.

2 CE Anyanechi, BDSaheeb (2013) The efficacy of tincture of benzoin compound in the management of extraction sockets of mesioangularly impacted mandibular third molar. Oral Surg 6: 137-141.

3 Visintini E, Angerame D, Constantinides F, Maglione M (2007) Peripheral neurological damage following lower third molar removal. A preliminary clinical study. Minerva Stomatol 56: 319-326.

4 Bui CH, Seldin EB, Dodson TB (2003) Types, frequencies, and risk factors for complications after third molar extractions. J Oral MaxillofacSurg 61: 1379-1389.

5 Tay AB, Go WS (2004) Effect of exposed inferior alveolar neurovascular bundle during surgical removal of impacted lower third molars. J Oral MaxillofacSurg 62: 592-600.

6 Ziccardi VB, Zuniga JR (2007) Nerve injuries after third molar removal. Oral MaxillofacSurgClin North Am 19: 105-115.

7 Loescher AR, Smith KG, Robinson PP (2003) Nerve damage and third molar removal. Dent Update 30: 375-382.

8 Merrill RG (1997) Prevention, treatment, and prognosis for nerve injury related to the difficult impaction. Dent Clin North Am 23: 471-488.

9 Pichler JW, Beirne OR (2001) Lingual flap retraction and prevention of lingual nerve damage associated with third molar surgery: a systematic review of the literature. Oral Surg Oral Med Oral Pathol Oral RadiolEndod 91: 395-401.

10 Wofford DT, Miller RI (1987) Prospective study of dyesthesia following odontectomy of impacted mandibular third molar molars. J Oral MaxillofacSurg 45: 15-19.
11 Rood JP, Shehab BAAN (1990) The radiological prediction of inferior alveolar nerve injury during third molar surgery. Br J Oral MaxillofacSurg 28: 20-25.

12 Pederson GW (2002) Oral surgery. Philadelphia: WB Saunder; 1988. (Quoted by Yuasa et al. Classification of surgical difficulty in extracting impacted third molars. Br J Oral MaxillofacSurg 40: 26-31.

13 Gargallo AJ, Buenechea IR, Gay EC (2000) Lingual nerve protection during surgical removal of lower third molars. A prospective randomized study. Int J Oral MaxillofacSurg 29: 268-271.

14 Wasiu LA, Lagos N (2006) Do pathologies associated with impacted lower third molars justify prophylactic removal? A critical review of the literature. Oral Surg Oral Med Oral Pathol Oral RadiolEndod 102: 448-452.

15 Yeh CJ (1995) Simplified split-bone technique for removal of impacted mandibular third molars. Int J Oral MaxillofacSurg 24: 348-350.

16 Sharma R, Srivastava A, Chandramala R. Nerve injuries related to mandibular third molar extractions. e J Dent 2: 146-152.

17 Andrew BGT, Wee SG (2004) Effect of exposed inferior alveolar neurovascular bundle during surgical removal of impacted lower third molars. J Oral MaxillofacSurg 62: 592-600.

18 Cheung LK, Leung YY, Chow LK, Wong MCM, Chan EKK, et al. (2010) Incidence of neuro-sensory deficits and recovery after lower third molar surgery: a prospective clinical study of 4338 cases. Int J Oral MaxillofacSurg 39: 320-326.

19 Elena QG, Eduard VC, Leonardo BA, Cosme GE (2005) Incidence and evolution of inferior alveolar nerve lesions following lower third molar extraction. Oral Surg Oral Med Oral Pathol Oral RadiolEndod 99: 259-264. 